\title{
A physical resilience conceptual model - contributions to gerontological nursing
}

\author{
Um modelo conceitual de resiliência física - contribuições para a enfermagem gerontológica \\ Un modelo conceptual de resiliencia física - contribuciones a la enfermería gerontológica
}

\section{Rafael Bernardes', Cristina Lavareda Baixinho'}

'Escola Superior de Enfermagem de Lisboa. Lisbon, Portugal.

\begin{abstract}
How to cite this article:
Bernardes R, Baixinho CL. A physical resilience conceptual model - contributions to gerontological nursing.
\end{abstract}

Rev Bras Enferm [Internet]. 2018;71(5):2589-93. DOI: http://dx.doi.org/10.1590/0034-7167-2017-0111

\section{Submission: 03-18-2017 Approval: 01-27-2018}

\section{ABSTRACT}

Objectives: To analyze and reflect on the potential applicability of the contribution of the physical resilience conceptual model of Whitson et al. in the care for older adults. Method: The present article of reflection was structured based on the consultation of articles and definition of inherent concepts, with analysis and reason of the potentialities of its application in geriatric nursing care. Results: Physical resilience is influenced by diverse stimuli. The identification of stressors and early intervention enable the delay of the functional capacity decline. In practice, the planning of interventions that depend on the innate capacity of older adults is of utmost importance. Conclusion: The trajectory outlined over a debilitating event is relevant to understand the factors that contribute to the development of frailty or pre-frailty conditions. This knowledge allows nurses to adjust their practice and contribute to the effectiveness of interventions and a better prevention of the frailty syndrome.

Descriptors: Motor Activity; Nursing; Disabled Persons; Frail Elderly; Dependence.

\section{RESUMO}

Objetivos: Analisar e refletir sobre a potencial aplicabilidade do contributo do modelo conceitual de resiliência física de Whitson e colaboradores no cuidado à pessoa idosa. Método: Este artigo de reflexão foi estruturado a partir da consulta de artigos e definição dos conceitos inerentes, com análise e fundamentação das potencialidades da sua aplicação no cuidado de enfermagem geriátrico. Resultados: A resiliência física é influenciada por diferentes estímulos. A identificação dos estressores e a intervenção precoce permitem atrasar o declínio da capacidade funcional. Na prática, é fundamental planejar intervenções que dependam da capacidade inata que a pessoa idosa apresenta. Conclusão: A trajetória traçada ao longo de um episódio debilitante é relevante para compreender os fatores que contribuem para o desenvolvimento de estados de fragilidade ou pré-fragilidade. Este conhecimento permite ao enfermeiro adequar a sua atuação e contribuir para a eficácia das intervenções e para uma melhor prevenção da síndrome da fragilidade.

Descritores: Atividade Motora; Enfermagem; Pessoas com Deficiência; Idoso Fragilizado; Dependência.

\section{RESUMEN}

Objetivos: Analizar y reflexionar sobre la potencial aplicabilidad de la contribución del modelo conceptual de resiliencia física de Whitson y colaboradores en el cuidado al anciano. Método: Artículo de reflexión estructurado partiendo de la consulta de artículos y definición de los conceptos inherentes, con análisis y fundamentación de las potencialidades de su aplicación en el cuidado de enfermería geriátrica. Resultados: La resiliencia física recibe influencias de diferentes estímulos. Identificar los estresores e intervenir precozmente permite atrasar la declinación de la capacidad funcional. En la práctica, resulta fundamental planificar intervenciones que dependan de la capacidad innata propia del anciano. Conclusión: El camino trazado durante un episodio debilitante es relevante para comprender los factores que contribuyen al desarrollo de estados de fragilidad o prefragilidad. Este conocimiento permite que el enfermero adecue su actuación y contribuye a la eficacia de las intervenciones y a una mejor prevención del síndrome de fragilidad. Descriptores: Actividad Motora; Enfermería; Personas con Discapacidad; Anciano Frágil; Dependencia.

\section{CORRESPONDING AUTHOR Rafael Bernardes E-mail: rafael.a.bernardes@campus.esel.pt}




\section{INTRODUCTION}

The concept of resilience is widely used in the nursing scientific literature, but not always with a universal definition, or even consensual. It is often conceptualized as a trait/singularity, which is determined by neurobiological, psychological, and social factors. It is also characterized as a trajectory ${ }^{(1)}$. Resilience is a characteristic/capacity to manage stress, remain well, recover, or even resist in the face of adverse events up to health changes by learning and adaptation ${ }^{(2)}$. Deep down, it is the response to stressful events( ${ }^{(2)}$.

This definition is partially adapted by other authors who define resilience as an ability, that is, the capacity of an individual to resist, recover, and grow in the face of stressors and demands that change over time ${ }^{(3)}$.

This concept was always applied in physics to express the elastic properties of a specific object. The same definition may be applied to individuals and referred to their capacity of response in the face of a potentially debilitating event. In this respect, resilience is defined as a trend for an individual to remain well or bounce back to a starting point considered healthful, in the face of an adverse event. Resilience is seen as a psychological construct characterized by adaptive attitudes and behaviors that enable an individual to remain psychologically well, or even withstand when exposed to stressful life events ${ }^{(4)}$.

Due to the concern to allow evaluating resilience, some authors have presented theories and models ${ }^{(1)}$. The present reflection brings the discussion on the physical resilience conceptual model ${ }^{(1)}$. This model may influence the clinical practice of nurses, as well as research, because it allows the definition of several indicators that facilitate the appreciation of individuals to experience a potentially debilitating event and the definition of interventions that promote physical resilience.

The guiding question of the present study was: "What are the potentialities of the physical resilience conceptual model of Whitson et al. in the care for older adults?" Grounded on the model's assumptions and elements, the present article of reflection was structured based on the consultation of articles on physical resilience and definition of inherent concepts, with analysis and reason of the potentialities of its application in geriatric nursing care.

Therefore, the objectives of the present study were to analyze the contribution of the physical resilience conceptual model of Whitson et al. ${ }^{(1)}$ and reflect on its potential applicability in older adults.

\section{DISABILITY, FRAILTY, AND PHYSICAL RESILIENCE}

The models, while abstract representations of a specific reality, help to think about something that does not match with that reality, but somehow try to simulate $i^{(5)}$. However, when relations are highly complex, such as in the case of rehabilitation processes and other human behavior areas, it is impossible to develop predictive models quantitatively ${ }^{(6)}$.

Conceptual models are based on a partial knowledge of reality and allow to think about behaviors of components included in complex systems. In fact, they allow to generally understand established relations. Finally, the experimental results may suggest that the models are changed or even discarded in detriment of new models $s^{(6)}$.

There are several models that focus on the terms disability and frailty. Both syndromes ${ }^{(7)}$ are common characteristics of the elderly population and share a multifactorial construct ${ }^{(8)}$. However, they present several differences that must be distinguished. The first term is often seen as a component of the second term ${ }^{(9)}$ and an important predictor of hospitalization; a difficulty or dependence on third parties to meet activities of daily living and instrumental life activities ${ }^{(8,10)}$. Disability may be the cause or consequence of frailty ${ }^{(8)}$ and the described correspondence is not consensual ${ }^{(10)}$. Disability is also often characterized, in certain contexts, as a social phenomenon ${ }^{(10)}$. Some authors ${ }^{(8,10)}$ report that disability and frailty have high chances of contributing to the development or progression of chronic diseases. The second term presented, "frailty", which has a strong association with disability, is often called physical frailty.

Frailty is also often seen as "accumulating deficits"(10). As previously mentioned, a frail condition may be an increased risk for adverse events ${ }^{(11)}$ such as falls, reduction of mobility, lesser independence, hospitalization, disability, and death. It is worth mentioning that the essential elements that define the frailty syndrome are weakness, reduced resistance, weight loss, reduced physical activity, and reduced walking speed ${ }^{(11)}$. An author adds that frailty is a characteristic defined by broad variances in the health status and a high risk of developing acute complications, such as infections, which may interrupt the rehabilitation program, cause a negative impact on the functional progress, and increase health costs ${ }^{(10)}$.

Resilience has much in common with this process, because it may be a defense mechanism of individuals with regard to environment demands. In other words, limitations in social roles and physical tasks, exacerbated by a singularity of the exterior, may be mitigated if the individual has a certain resilience "level".

In the case of older adults, resilience has to be analyzed in a bio-functional, economic, demographic, and health perspective $^{(1)}$. Being older increases the chance and risk of having more diseases, as well as organic dysfunctions associated, which in turn, may lead to functional limitations, disability, or death (biofunctional perspective) $)^{(1)}$. In addition, physical decline associated with age, especially loss of independence, may be devastating for individuals and economically burdensome for society (economic perspective $)^{(1)}$. As a complement, at the same time the average lifespan increases, healthcare systems and communities are challenged to find sustainable and effective ways to promote healthy ageing, defined as the maintenance of physical, mental, and social well-being (demographic and health policy perspective) $)^{(1)}$.

In theory, there are several ways of achieving a desirable resilience state. Two of the ways that may be followed are physical well-being (physical fitness) and robustness (hardiness). The last is defined as an attitude (or a set of attitudes) or even a personality trait that helps individuals to integrate stressors into their personal growth, instead of turning them into negative events ${ }^{(3)}$. Because the model analyzed in the present study focuses on the physical dimension, the second way suggested is discarded, even knowing that psychological factors such as self-esteem and self-efficacy are determinants of physical activity. 
The planning of interventions that aim at delaying the beginning of a frail condition in functionally independent older adults corresponds to the primary prevention level. However, interventions directed towards a vulnerable group with disability signs, in order to prevent late deterioration of the present condition, correspond to the secondary prevention level ${ }^{(9)}$.

Physical frailty, considered a physiological vulnerability state, has a particular use in research. The frailty index (FI) is a predictor of adverse advents and a valuable and versatile instrument ${ }^{(2)}$.

Knowing that this Fl instrument may help predict a greater vulnerability condition such as frailty, and consequently prevent hospitalization cases or other more serious adverse events such as death ${ }^{(9-10)}$, it is worth understanding what may be at stake when the problem is not to develop frailty, but pre-frailty. In other words, it will be interesting to understand if it is possible to enhance resilience, which is an innate human characteristic, in order to maintain the individual in a previous condition to pre-frailty, that is, of physical robustness.

Still not knowing the accurate definition of the pre-frailty status, from this theoretical framework, it is possible to begin understanding it from the resilience perspective. Therefore, from what was previously mentioned regarding this concept, it will make sense to include the term "phrailty" (physical frailty), in case there is, indeed, a state of pure physiological vulnerability.

It would be impossible to detect a similar state to this, when speaking of physiological vulnerability, before any apparent clinical manifestation, although the same may be detected prior to the emergence of the disability. Therefore, in order to have some way to quality the event, the following practical definition must be considered: physical frailty and total functional frailty (F-frailty or full-blown functional frailty) are like overlapped conditions inside a spectrum that embraces both the definition presented, which is much based on physiological commitment, and the traditional notion of frailty, which considers functional limitations and external factors such as environment and social support ${ }^{(2)}$.

Consequently, physical resilience seems to be a sensitive switch, when stimulated, for the transition among different frailty conditions.

\section{THE CONCEPTUAL MODEL OF PHYSICAL RESILIENCE}

Physical resilience is influenced by factors or psychosocial "contributors", genetic factors, physiological factors (physiological reserve), life experiences, and environment ${ }^{(1)}$. From these five factors, at least three may be considered as objective (genetic, physiological, and environment) and two as subjective (psychosocial and life experiences). According to this classification, objective factors are quantitative and subjective factors are qualitative.

The objective of the practical application of this conceptual model is to maintain health, especially function ${ }^{(1)}$, which implies minimizing the effects of damage, disease, or other inevitable constraints.

This may be done by optimizing the resilience inherent to an individual, thus quantifying it according to certain criteria that must be defined by research.

However, the conceptual model of physical resilience (Figure 1) suggests three approaches in the quantification of physical resilience, based on its interaction with an exterior stimulus, which produces an outcome.

Therefore, resilience is influenced by stressors or natural stimuli produced by the abovementioned factors and, as fruit of this interaction, results in a specific outcome. Based on this, it is possible to evaluate and measure physical resilience by means of three ways: (1) phenotype of the individual or group of individuals (community) - frail (frailty), robust, and "fatigability"; (2) discrepancy in age among individuals or groups of individuals - biological age versus chronological age; and finally, (3) the outlined trajectory - resilient or resistant ${ }^{(1)}$.

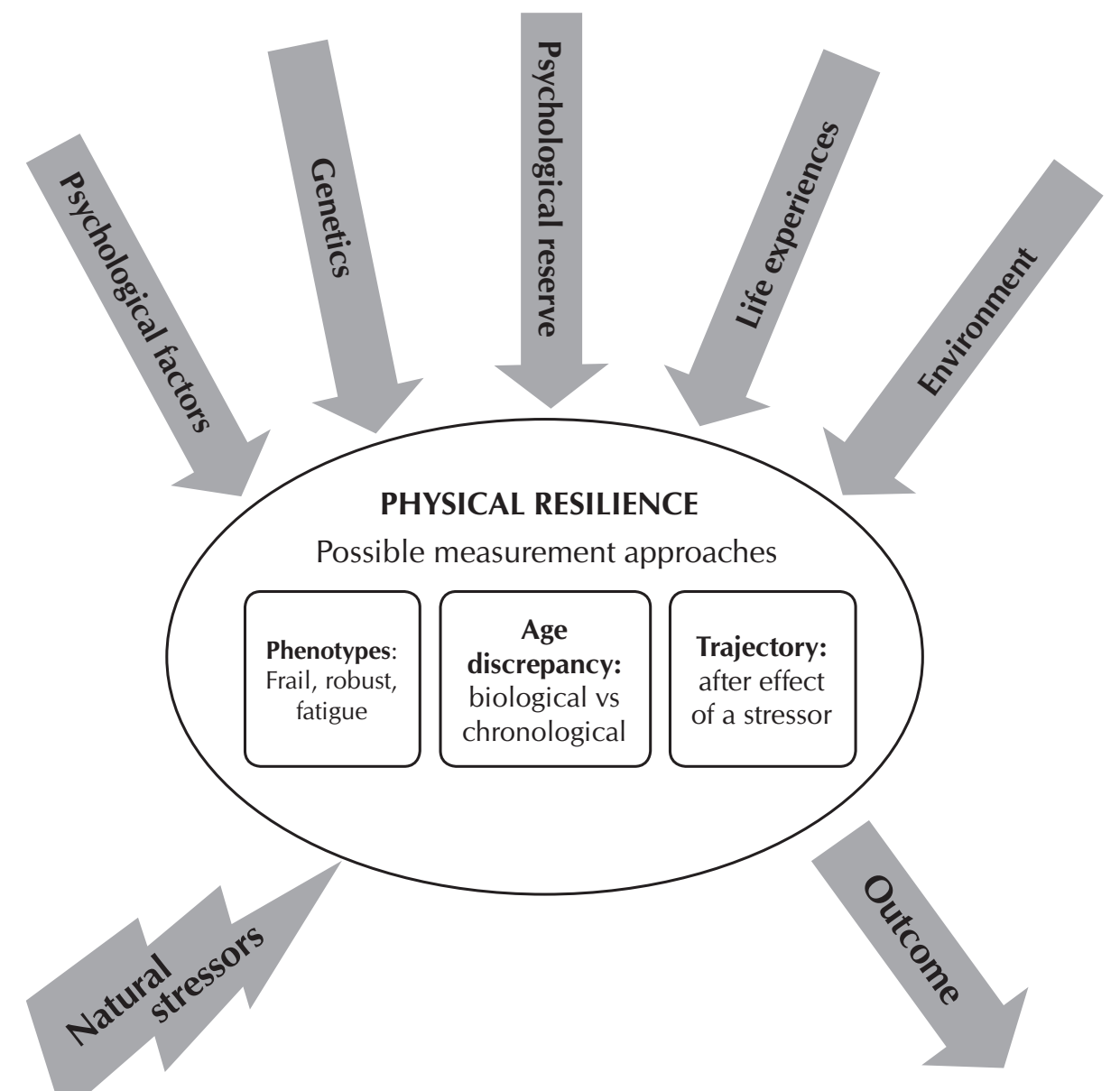

Source: Whitson et al. (2016) $)^{(1)}$

Figure 1 - Conceptual model of physical resilience, Lisbon, 2017 
It is particularly interesting to note the approach from the phenotype point of view and the functional trajectory point of view, which is the most common indicator of physical resilience $^{(1)}$. In addition, the concept of phenotype of frailty ${ }^{(9-10)}$ is included in the Fried Frailty Index (FFI), which considers it "multifactorial", just like the model. However, this index allows the quantification of vulnerability associated with this status ${ }^{(8)}$.

The intervention at resilience level must act at the level of the factors proposed by the model ${ }^{(1)}$ and must delay the functional capacity decline associated with age, in addition to extend a life free of disability ${ }^{(8)}$.

In association with the FFI, the model must allow to quantify the physical resilience level, by determining the corresponding phenotype. Therefore, it will be possible to outline specific interventions at the level of frailty criteria and prevent hospitalization, thus preventing functional decline associated with hospitalization.

\section{THE CONCEPTUAL MODEL OF PHYSICAL RESILIENCE: CHALLENGES TO GERONTOLOGICAL NURSING}

Nursing, as a scientific course, has health-disease processes and responses to alteration in health status as object of study. In the specific case of gerontological nursing, the construction of knowledge to meet individual needs of each older adult, most times transitions of different kinds with simultaneous or sequential multiple standards, regardless of being or not related $^{(12)}$, makes the practice of nurses complex and implies a multidisciplinary approach. This multidisciplinary approach must be a leading instrument in search for changes allowing to add knowledge and lead to efforts in the knowledge development process in the healthcare area of older adults ${ }^{(13)}$. Because frailty is a complex event that implies problem-solving, the use of a multidisciplinary team covers all prevention levels.

Prior to the prescription of nursing therapy interventions, it is important to identify determinants, which may facilitate or make it difficult for older adults to achieve a healthy transition, through the development of new skills (mastery) or through reformulation of their identities ${ }^{(12)}$, that is, complex interventions that must especially focus on the promotion of physical activity and appropriate nutrition.

During transition processes, natural stressors described in the presented model may induce alterations that need a differentiated assessment.

In fact, when older adults experience a potentially debilitating event, the probability of entering a pre-frailty state is high. It means a fast debilitation of physiological reserve, which must interact with a phenotype. This is where nurses must act, with a focus on the prevention of a pre-frail reaction to a potentially debilitating event, thus increasing the chance of a successful transition process.

The prompt identification of how older adults respond to specific patterns of potentially debilitating events allows the prediction of a hospitalization trajectory (resilient, which is desirable, or more likely chronic or lengthy, for example), promoting determinants favorable to the transition and controlling, minimizing, or eliminating inhibiting factors.

Therefore, nursing therapies may integrate the diverse types of trajectory defined in the model and help patients achieve positive health outcomes. In addition, they can be seen in a perspective of care continuity, which is included in the trajectory. In other words, if there is a record, for example, of outcomes and physical resilience of older patients during their hospitalization or a potentially adverse event, nurses may have access to previous trajectories of these patients, allowing them to plan care based on the criteria described, thus early preventing pre-frailty conditions.

If the trajectory to be covered during hospitalization and after hospital discharge is not well-prepared, the chance of developing a frailty syndrome is high, which means a higher risk of adverse outcomes ${ }^{(11)}$.

In addition, when the trajectory to be covered is considered an important property of the transition experience, prevention at pre-frailty level may be a facilitating factor of that experience, when increasing preparation and knowledge level of patients regarding their current condition and how it can be managed.

\section{FINAL CONSIDERATIONS}

Resilience, as an ability to manage one's own health in the face of adverse events, is influenced by several factors. It is known that hospitalization is a possible stressful event and may seriously debilitate the health status, for example, reducing physiological reserve.

For nurses in the gerontological area, it is always important to consider that states of fatigue are common, which may lead to a phenotype such as frailty. The physical conditions mentioned, in interaction with reduced physiological reserve of the elderly cause significant complications and situations of increased vulnerability, such as falls. Consequently, events such as immobility and social isolation emerge or worsen. However, frail older adults present characteristics as reduced resistance, weakness, and reduced walking speed, which increase the risk of hospitalization, disability, and death.

Knowing that these characteristics may emerge, nurses, considering the model presented, will have access to "how resistant" or "how frail" an individual is. This means an increased capacity for prevention and a longer time to outline, together with the patient and family, the most appropriate interventions. If nurses are able to know the elderly during their admission through their phenotype, in addition to the feedback regarding their response to previous hospitalizations, they may predict the type of trajectory and outline a personalized care plan.

For further research, it will be important to define what is a potentially debilitating event, considering that there is a definition for potentially traumatic events ${ }^{(4)}$. It will be interesting to see if the FFI or another similar instrument is able to generate a score that limits a practical definition of the concept.

Although the term resilience is defined under several points of view, it does not present the duality of the term frailty, which is both an individual's characteristic and a phenotype that may be seen, qualified, and quantified. The objective of the model is to try to make this resilience evaluation, but whose instruments of quantification do not yet exist. Therefore, it would be relevant to find or develop an index/scale that includes the indicators of the model, and that has a number that allows to compare resilience levels as output.

Furthermore, with regard to the model presented, it would be interesting to see if the ageing process is considered a stressor and, if so, to which extent. 


\section{REFERENCES}

1. Whitson HE, Duan-Porter W, Schmader KE, Morey MC, Cohen HJ, Colón-Emeric CS. Physical resilience in older adults: systematic review and development of an emerging construct. J Gerontol A Biol Sci Med Sci [Internet]. 2016[cited 2017 Mar 17];71(4):489-95. Available from: https://dx.doi.org/10.1093/gerona/glv202

2. Whitson HE, Purser JL, Cohen HJ. Frailty Thy Name Is Phrailty? J Gerontol A Biol Sci Med Sci[Internet]. $2007[$ cited 2017 Mar 17];62(7):728-30. Available from: https://www.ncbi.nlm.nih.gov/pmc/articles/PMC2648133/

3. Deuster P, Silverman MN. Physical fitness: a pathway to health and resilience. US Med Dep J[Internet]. 2013[cited 2017 Mar 17];2435. Available from: nhttps://www.thefreelibrary.com/Physical + fitness $\% 3 \mathrm{~A}+\mathrm{a}+$ pathway + to + health + and + resilience.-a0352490358

4. Bonanno GA, Westphal M, Mancini AD. Resilience to Loss and Potential Trauma. Annu Rev Clin Psychol[Internet]. 2011[cited 2017 Mar 17];7:511-35. Available from: https://www.annualreviews.org/doi/abs/10.1146/annurev-clinpsy-032210-104526

5. Rocha PK, Prado ML, Silva DMGV. Pesquisa Convergente Assistencial: uso na elaboração de modelos de cuidado de enfermagem. Rev Bras Enferm[Internet]. 2012[cited 2017 Mar 17];65(6): 1019-25. http://dx.doi.org/10.1590/S0034-71672012000600019.

6. Brandt Jr EN, Pope AM. Enabling America: assessing the role of rehabilitation science and engineering [Internet]. Washington: National Academies Press; 1997[cited 2017 Mar 17]. Available from: https://www.ncbi.nlm.nih.gov/books/NBK233576/

7. Song J, Lindquist LA, Chang RW, Semanik PA, Ehrlich-Jones LS, Lee J, et al. Sedentary behavior as a risk factor for physical frailty independent of moderate activity: results from the osteoarthritis initiative. Am J Public Health[Internet]. 2015 [cited 2017 Mar 17];105(7):1439-45. Available from: https://dx.doi.org/10.2105/AJPH.2014.302540

8. Topinková E, Aging disability and frailty. Ann Nutr Metab [Internet]. 2008[cited 2017 Mar 17];52(suppl.1):6:11. Available from: https://dx.doi.org/10,1159/000115340

9. Sternberg SA, Schwartz AW, Karunananthan S, Bergman H, Clarfield AM. The identification of frailty: a systematic literature review. J Am Geriatric Soc[Internet]. 2011[cited 2017 Mar 17];59(11):2129:38. Available from: https://dx.doi.org/10.1111/j.1532-5415.2011.03597.x

10. Fried LP, Ferrucci L, Darer J, Williamson JD, Anderson G. Untangling the concepts of disability, frailty, and comorbidity: implications for improved targeting and care. J Gerontol A Biol Sci Med Sci [Internet]. 2004[cited 2017 Mar 17];59(3):255-63. Available from: http://www.hopkinsmedicine.org/geriatric_medicine_gerontology/_downloads/readings/section10_2.pdf

11. Rockwood K, Mitnitski A. Frailty in relation to the accumulation of deficits. J Gerontol A Biol Sci Med Sci [Internet]. 2007[cited 2017 Mar 17];62(7):722-7. Available from: https://www.researchgate.net/publication/6204727_Frailty_in_Relation_to_the_Accumulation_of_Deficits

12. Meleis Al. Transitions theory: middle range and situation specific theories in research and practice. New York: Springer Publishing Company; 2010.

13. Camacho ACLF. A gerontologia e a interdisciplinaridade: aspectos relevantes para a enfermagem. Rev Latino-Am Enfermagem[Internet]. 2002[cited 2017 Oct 12];10(2):229-33. Available from: http://dx.doi.org/10.1590/S0104-11692002000200016 